Article

\title{
The Performance of TiAlSiN Coated Cemented Carbide Tools Enhanced by Inserting Ti Interlayers
}

\author{
Guodong Li ${ }^{1}$, Liuhe $\mathrm{Li}^{1}{ }^{1 *}$, Mingyue Han ${ }^{1}$, Sida Luo ${ }^{1}{ }^{1}$, Jie Jin ${ }^{2}$, Lei Wang ${ }^{1}$, Jiabin Gu ${ }^{1}$ \\ and $\mathrm{Hu} \mathrm{Miao}^{1}$ \\ 1 School of Mechanical Engineering and Automation, Beihang University, Beijing 100191, China \\ 2 School of Mechanical, Electronic and Control Engineering, Beijing Jiaotong University, Beijing 100191, China \\ * Correspondence: liliuhe@buaa.edu.cn; Tel.: +86-10-8231-8135
}

Received: 31 July 2019; Accepted: 19 August 2019; Published: 22 August 2019

\begin{abstract}
To enhance the cutting performance of TiAlSiN coated cemented carbide tools by inserting Ti interlayers and to explore their mechanism, TiAlSiN/Ti multilayer coatings with different Ti thicknesses, including $0 \mathrm{~nm}, 25 \mathrm{~nm}, 50 \mathrm{~nm}, 100 \mathrm{~nm}$, and $150 \mathrm{~nm}$, were deposited onto cemented carbide (WC-10 wt\%, Co) substrates by high power impulse magnetron sputtering (HiPIMS). The microstructure, hardness, grain orientation, residual stress, adhesion, and toughness of those coatings were measured, and the cutting performance against Inconel 718 was analyzed. Meanwhile, finite element method (FEM) indentation simulations were performed to gain detailed insight into the effects of Ti interlayer thickness on mechanical properties of TiAlSiN/Ti multilayer coatings. Results demonstrated that mechanical properties of TiAlSiN multilayer coatings were significantly changed after the Ti interlayer was introduced, and the multilayer coating \#M2 with $25 \mathrm{~nm}$ Ti layer showed the excellent toughness and adhesion without sacrificing hardness too much. As Ti interlayer thickness increased, both toughness and adhesion decrease owing to the plastic mismatch between individual layers, and these changes were discussed detailedly with finite element method. Moreover, the result of the cutting experiment also revealed that the tool flank wear $V b$ can be reduced by the multilayer structure. This improvement is believed to be due to the increasing toughness, which alleviated the damage caused by the continuous impact load of hard phases generated by Inconel 718 during cutting.
\end{abstract}

Keywords: cutting performance; fracture toughness; tough-yet-hard coating

\section{Introduction}

Inconel 718, with its capability of maintaining superior, excellent mechanical properties under extreme conditions, is a type of superalloy widely used in the aircraft and nuclear industries. However, it is also characterized by high work-hardening tendency, the appearance of abrasive carbide particles, built-up edge formation, and low thermal conductivity [1-3]. Over the past years, although considerable researches have been conducted worldwide, the machining of Inconel 718 is still a tricky issue. One of the promising solutions is to protect the surface of cutting tools with superhard coatings [4].

Extensive researches have been made on TiAlN hard coatings in cutting Inconel 718, as this material possesses high hardness, high wear resistance, high high-temperature stability, and superior mechanical properties [5-7]. With Si added, TiAlSiN coatings have better mechanical properties than TiAlN due to the microstructure of TiAlSiN, who's crystalline nc-TiAlN phases are wrapped in amorphous a-Si3N4 phase at nanometer scale [8,9]. This kind of microstructure can refine grains of TiAlN, and help improve the hardness of the coatings due to the Hall Patch effect [10-12]. Besides, a lot of papers demonstrate that the high-temperature oxidation resistance [13,14], thermal stability [15], and tribological behavior [16-18] of the coatings are improved after Si is added to TiAlN coatings. 
All these characteristics of TiAlSiN meet the cutting requirements of Inconel 718, which is characterized by severe work-hardening and high cutting heat. However, until now, researchers seldom study the application of TiAlSiN coatings in the machining of Inconel 718.

During the cutting process, Inconel 718 will generate a quantity of hard phases (TiC, $\mathrm{NbC}$, MoC) $[19,20]$, which can produce a continuous and intensive shock load on the coatings of tools. Under such conditions, the coatings have to possess higher toughness to resist such shock. However, TiAlSiN with high-level hardness often has low toughness and brittle nature [21,22]. Therefore, improving the toughness of TiAlSiN coatings without sacrificing too much hardness is a necessary condition for its wider application in the cutting of Inconel 718. The main methods to increase the toughness of hard coatings include introducing a toughening agent, utilizing phase transformation, and introducing toughening agents, compressive stress, or the multilayer structure [22].

The multilayered structure consisting of alternating ceramic/metal materials is considered as an effective way to improve the toughness of the hard coating. The main toughening mechanisms can be summarized as the relaxation of the strain field around the crack tip through the ductile phase, crack deflection at the interface among the sub-layers, and interface opening or delamination to reduce the stress concentration [8,23-25]. Vogli et al. [26] studied the residual stresses and mechanical properties of multilayer TiAlN/Ti with various designs and found that the multilayer coatings with the thickest ceramic layers have the highest hardness and the lowest wear rate, as well as the minimum compressive residual stress. Bonu et al. [27] investigated the mechanical properties of multilayer Ti/TiN coating with various bilayer thicknesses. Their results showed that the film with a bilayer thickness of $7.5 \mathrm{~nm}$ demonstrated the highest hardness and highest erosion resistance at $400{ }^{\circ} \mathrm{C}$. However, there are few studies investigating ceramic/metal multilayered coatings with TiAlSiN nanocomposite coatings. In view of the above, TiAlSiN/Ti multilayer coatings with varying Ti thicknesses were synthesized in an attempt to overcome the innate brittleness of TiAlSiN nanocomposite coatings, and explore the thickness-dependent mechanical properties.

High power impulse magnetron sputtering (HiPIMS) has received extensive interest from researchers because of its high-level ionization rate (70\% for copper) of sputtered target material since its introduction by Kouznetsov et al. [28]. The characteristics of high metal ion concentrations and multiple ionization not only make it possible to deposit coatings with increased density, improved crystallinity, and excellent adhesion, but also enable more direct control over the deposition process [29]. Even for complex-shaped tools, the HiPIMS-coating can obtain good thickness homogeneity [30], because a large number of ions are attracted on the whole surface of substrates by adjusting the bias voltage [31] and the shadowing effect becomes weak. Therefore, the HiPIMS technology has great application potential in the field of cutting tools.

In this research, TiAlSiN/Ti multilayer coatings with fixed TiAlSiN layer thickness and varied Ti layer thicknesses were prepared by HiPIMS. Then, a systematic investigation on the microstructures and mechanical properties of those coatings was conducted, and the cutting performance against Inconel 718 was studied. Moreover, the finite element method (FEM) was used to further identify the effect of Ti layer thickness on the mechanical properties of TiAlSiN/Ti multilayer coatings. The results showed that the hardness, residual stress, toughness, and adhesion of TiAlSiN coating were significantly changed after Ti interlayers were inserted, and that the multilayer coating with $25 \mathrm{~nm}$ Ti interlayer exhibited excellent mechanical properties. The cutting performance of TiAlSiN coatings also gained remarkable improvement by designing TiAlSiN/Ti multilayer structure. This study not only provides a method to improve the cutting performance of TiAlSiN coated tool in cutting Inconel 718, but also can be used as a reference for the application of brittle coatings under high impact load conditions. 


\section{Experimental Details}

\subsection{Coating Preparation}

The deposition process was accomplished in a hybrid deposition apparatus with a base pressure of $2 \times 10^{-3} \mathrm{~Pa}$, as shown in Figure 1 . All the coatings were deposited on the uncoated cemented carbide

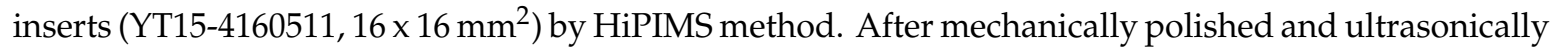
cleaned, all substrates were further cleaned by glow discharge for $30 \mathrm{~min}$ at $1.5 \mathrm{~Pa}$ Ar pressure and $1000 \mathrm{~V}$ substrate bias voltage in order to ensure the maximum degree of cleanliness. During the coating preparation, the deposition was carried out by a hybrid ion implantation and deposition apparatus with a mixture of high purified (99.999\%) argon and nitrogen gases [32] at a deposition temperature regulated at $150{ }^{\circ} \mathrm{C}$. The apparatus was equipped with $\mathrm{Ti}_{0.64} \mathrm{Al}_{0.3} \mathrm{Si}_{0.06}$ and $\mathrm{Ti}$ targets (99.99\% purity) in the form of rectangular plates mounted vertically. The pulse width and frequency of HiPIMS were set at $200 \mu$ s and $50 \mathrm{~Hz}$, respectively. When the TiAlSiN layer was deposited, bias voltage, supply voltage, and pressure were kept at $400 \mathrm{~V}, 950 \mathrm{~V}$, and $0.8 \mathrm{~Pa}$, respectively, while those parameters were set as $0 \mathrm{~V}$, $850 \mathrm{~V}$, and 0.6 Pa for Ti layer deposition. Meanwhile, in order to maintain high hardness, the thickness of TiAlSiN layers was designed to be larger than that of Ti layers. Moreover, nitrogen ion implantation technique was employed prior to TiAlSiN deposition to improve the adhesion. The substrate was moved in a circular motion between the two sputtering targets using the stepper motor, which took about $10 \mathrm{~min}$ to switch the power. Based on the above-mentioned processing parameters, the TiAlSiN layer thickness was maintained at $270 \mathrm{~nm}$. The deposition time was adjusted so as to have a Ti sublayer thickness of $0 \mathrm{~nm}, 25 \mathrm{~nm}, 50 \mathrm{~nm}, 100 \mathrm{~nm}$, and $150 \mathrm{~nm}$. The schematic drawing of the TiAlSiN/Ti multilayer coatings is summarized in Figure 2.

1 Mass Flow control
2,8 Cooling water
3 Substrate
4 Holder
5 Turntable
6 Pumps
7 DC Bias
9 Vacuum Chamber
10,11 Magnetron

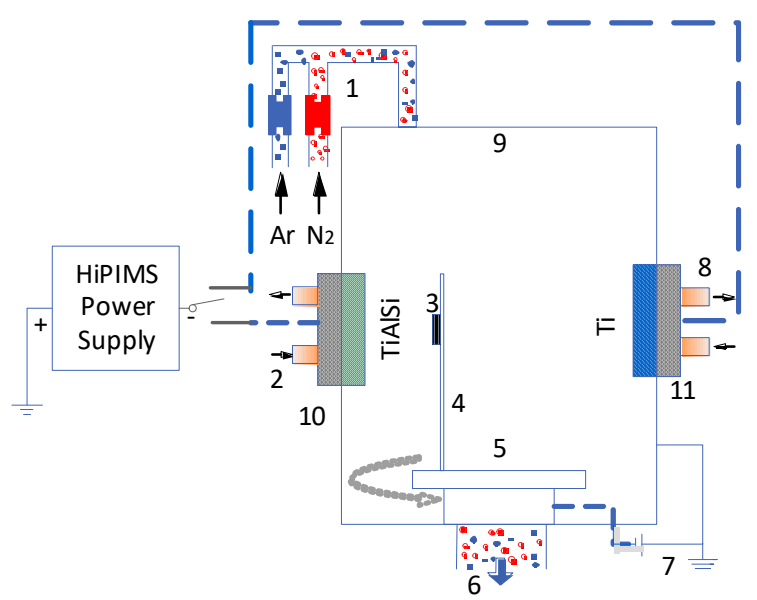

Figure 1. Deposition apparatus for TiAlSiN/Ti multiayer coatings.

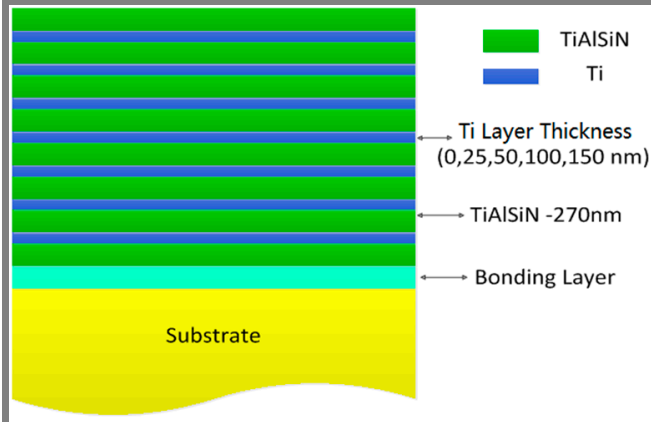

Figure 2. The schematic drawing for TiAlSiN/Ti multilayer coatings. The number of TiAlSiN and Ti sublayers is eight and seven, respectively. 


\subsection{Coating Characterization}

All TiAlSiN/Ti multilayer coatings were characterized by using a series of analytical techniques. Scanning electron microscope (SEM-ZEISS-Gemini SEM 500, Oberkochen, Germany) was used to acquire the cross-sectional morphology, as well as the thickness of coatings. In order to analyze the phase and crystal structures, X-ray diffractometry (XRD, D/Max 2500, Rigaku, Tokyo, Japan) with $\mathrm{CuK} \alpha$ radiation $\left(\lambda=1.54 \AA\right.$ ) was studied. In addition, the residual stress was analyzed by the $2 \theta-\sin ^{2} \psi$ method [33]. According to the test requirements, the $2 \theta$ of measured peaks needs to be more than $60^{\circ}$, thus the (201) peak $\left(2 \theta=84.08^{\circ}\right)$ of WC (substrate) was chosen in this research. Nanoindentation tester (Nano-Indentor, Agilent-XP/G200, Nano-Indentor XP, Agilent, Milpitas, CA, USA) with a load precision of $50 \mathrm{nN}$ was also used to measure nano-hardness and modulus of the coatings. The continuous stiffness method (CSM) [34] was adopted to obtain displacement-hardness values from initial to final indentation depth. The average hardness was calculated by hardness-displacement curves collected at the indentation depth of 30-300 $\mathrm{nm}$ from six random sites. The measured results were showed in Table 1, where $\mathrm{H}$ and $\mathrm{E}$ are the hardness and elasticity modulus measured by nanoindentation tester, the HRM is the hardness value calculated by the mixture formula (Equation (3)), and H/E represents elastic strain to failure [35]. Rock-well indentation with a $C$ tip (200 $\mu$ m radius) was accomplished to evaluate the adhesion strength. The indentation toughness was evaluated using a micro Vickers tester (Vickes-Indentor, Wolpert-401MVD, Chicago, IL, USA) with an applied load of $100 \mathrm{~g}$

Table 1. Thickness of Ti interlayer and mechanical properties of all the samples.

\begin{tabular}{ccccccccc}
\hline Sample & $\begin{array}{c}\text { Thickness of Ti } \\
\text { Interlayer } \\
(\mathbf{n m})\end{array}$ & $\begin{array}{c}\boldsymbol{H} \\
\mathbf{( G P a )}\end{array}$ & $\begin{array}{c}\boldsymbol{H}_{\mathbf{R M}} \\
\mathbf{( G P a )}\end{array}$ & $\begin{array}{c}\boldsymbol{E} \\
\mathbf{( G P a )}\end{array}$ & $\mathbf{H} / \boldsymbol{E}$ & Plasticity & $\begin{array}{c}\text { Residual } \\
\text { Stress } \\
\mathbf{( M P a})\end{array}$ & Rockwell \\
\hline \#S1 & 0 & 34 & - & 367 & 0.093 & 0.43 & -78.0 & $\mathrm{H} 6$ \\
\#M2 & 25 & 31 & 32.0 & 277 & 0.112 & 0.51 & -77.8 & $\mathrm{H} 2$ \\
\#M3 & 50 & 27 & 30.3 & 286 & 0.094 & 0.52 & -59 & $\mathrm{H} 4$ \\
\#M4 & 100 & 24 & 27.5 & 265 & 0.091 & 0.54 & -58.7 & $\mathrm{H} 6$ \\
\#M5 & 150 & 19 & 25.33 & 227 & 0.083 & 0.68 & -66.4 & $\mathrm{H} 5$ \\
\#S6 & Monolayer Ti & 7.5 & - & 190 & - & 0.85 & - & - \\
\hline
\end{tabular}

\subsection{FEM Numerical Simulation}

Indentation process of all the coatings was simulated by the finite element model (FEM) with software ABAQUS (Abaqus/CAE2018, Dassault Systems, Johnston, RI, USA), and the axisymmetric simulation model was used to save the computation time (Figure 3). The thickness of TiAlSiN monolayer coating (\#S1) and bonding layer were $2160 \mathrm{~nm}$ and $250 \mathrm{~nm}$, respectively. The thickness of TiAlSiN sublayers of the multilayer coatings was $270 \mathrm{~nm}$ while that of Ti sublayers was set as $25 \mathrm{~nm}$, $50 \mathrm{~nm}, 100 \mathrm{~nm}$, and $150 \mathrm{~nm}$, respectively. To ensure calculation precision, the mesh sizes of TiAlSiN and Ti layers were set as $20 \mathrm{~nm}$ and $5 \mathrm{~nm}$, respectively, and the 2D, 4-node structural solid element was used in all the finite element models. The elasticity modulus was based on the nano-hardness test of TiAlSiN and Ti layers (Table 1) The indenter was modeled as analytical rigid without friction with the coating surface, and its semi-vertical angle in the vertical direction was set as $75^{\circ}$. The maximum indentation depth was set as $600 \mathrm{~nm}$. 


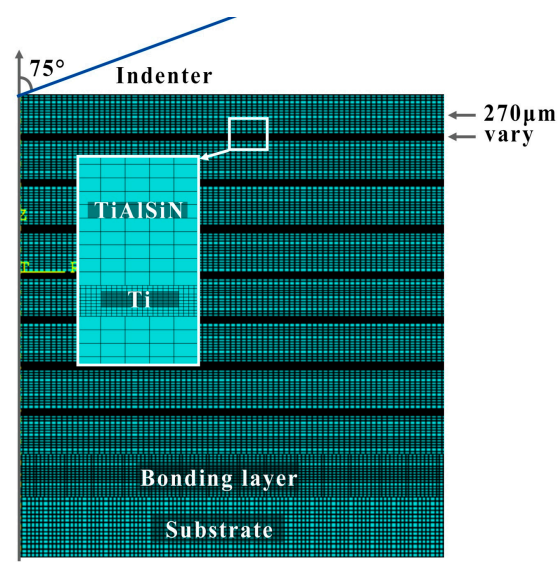

Figure 3. Finite element model geometry of TiAlSiN/Ti multilayer coatings.

\subsection{Cutting Experiments}

The Inconel 718 round bars ( $45 \mathrm{~mm}$ in diameter and $200 \mathrm{~mm}$ in length) served as the material in this study. Prior to each test, the workpiece would be prepared by removing an approximately 1.5-mm-thick layer from the outside surface, so as to eliminate any effect exerted by workpiece surface inhomogeneities on the experimental results. This is followed by wet turning tests conducted on a CGK6125A CNC lathe Machine, with the cutting depth $V_{p}$ set as $0.5 \mathrm{~mm}$, the feed rate $f_{a} 0.08 \mathrm{~mm} / \mathrm{r}$ and the cutting speed as high as $50 \mathrm{~m} / \mathrm{min}$. Since the tool's flank wear $\left(V_{b}\right)$ is an important parameter used to evaluate the failure of tools, it was defined as the average width of the middle position in flank's banded wear zone In order to compare the initial segment wear of the coated tools, all tools were required to turn the bars for $180 \mathrm{~s}$ under the same processing conditions and the tool flank wear $V_{b}$ was observed every $30 \mathrm{~s}$ under a standard optical microscope so as to monitor the wear of coated tools.

\section{Results and Discussion}

\subsection{Microstructure and Residual Stress}

The cross-sectional morphologies of TiAlSiN coatings with varied thicknesses of Ti layers $(0 \mathrm{~nm}$, $25 \mathrm{~nm}, 50 \mathrm{~nm}, 100 \mathrm{~nm}, 150 \mathrm{~nm}$ ) were observed by SEM. The TiAlSiN/Ti multilayer structure could be identified clearly, which agrees well with the schematic representations shown in Figure 2. As shown in Figure 4a, the monolayer TiAlSiN coating has a dense structure and no columnar crystal structure, which is consistent with the structure of nanocomposite (nc-TiAlN/a-Si3N4) found by some researchers [36]. From Figure 4, it can be seen clearly that the thickness of Ti layers of Samples \#M2 to \#M5 increases gradually, and Ti layers in \#M5 are observed to demonstrate the columnar crystal structure.

Figure 5 illustrates the XRD patterns of investigated TiAlSiN monolayer and TiAlSiN/Ti multilayer coatings. According to Figure 5, these preferential orientations are in agreement with TiN (JCPDF\#87-0631), Ti 3 AlN (JCPDF\#37-1140), Ti (JCPDF\#44-1294), $\mathrm{Si}_{3} \mathrm{~N}_{4}$ (JCPDF\#51-1334), and WC (JCPDF\#89-2727) from ICCD cards. Moreover, we also found that there were no AlN phases in the $\mathrm{XRD}$ results due to the high ratio of $\mathrm{Ti} / \mathrm{Al}$, implying that the $\mathrm{Al}$ element is likely to exist in the form of $\mathrm{Ti}_{3} \mathrm{AlN}$ compound with NaCl-type crystal structure [37]. (111), (200), and (220) planes of TiN and $\mathrm{Ti}_{3} \mathrm{AlN}$ phases are identified in Figure 5a. It is well known that the preferred orientation of the film is decided by the lowest overall energy condition resulting from a critical competition between the strain energy $\left(U_{\mathrm{hkl}}\right)$ and surface energy $\left(S_{\mathrm{hkl}}\right)$ [38]. The (111) plane has the smallest strain energy among three principal orientations since (111) plane possess the lowest elastic moduli $E$ (refer to Equation (1)), and the $(200)$ plane has the lowest surface energy in the fcc lattice of NaCl-type crystal structure $[38,39]$ as it 
has the lowest number of broken bonds $\left(n_{h k l}\right)$ per square centimeter (refer to Equation (2)). Under the same principal stresses, the strain energy can be expressed as

$$
U_{h k l}=\varepsilon^{2} E(1-v)
$$

where $E$ is the Young's modulus, $v$ the Poisson ratio and $\varepsilon$ the strain in the plane. The surface energy can be expressed as

$$
S_{h k l}=6.5 * 10^{-19} n_{h k l} / z \mathrm{~J} \mathrm{~cm}^{-2}
$$

where $n_{\mathrm{hkl}}$ denotes for the number of broken TiN or TiAlN bonds per square centimeter for different orientations, and $z$ is the coordination.
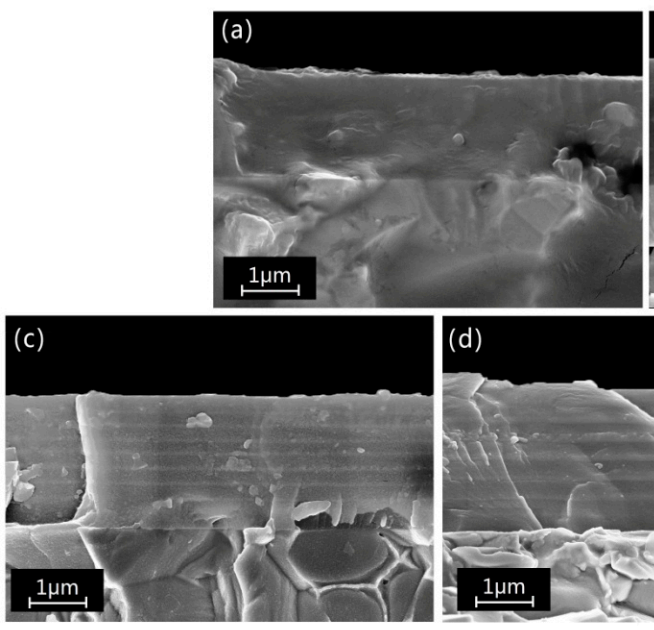

\section{(b)}
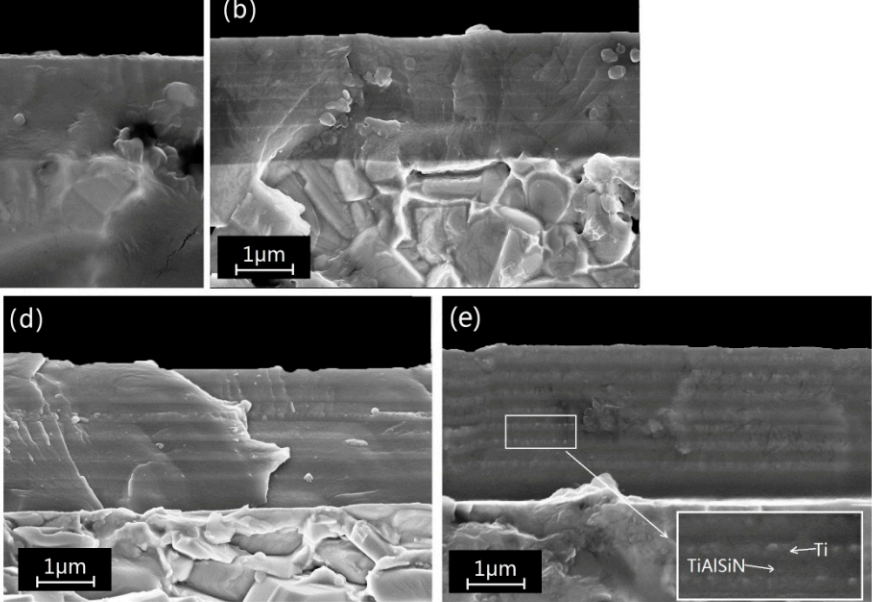

Figure 4. Cross-section of Scanning electron microscope (SEM) images of TiAlSiN/Ti coatings with different Ti thicknesses (a) \#S1 (Ti-0 nm), (b) \#M2 (Ti-25 nm), (c) \#M3 (Ti-50 nm), (d) \#M4 (Ti-100 nm), (e) \#M5 (Ti-150 nm).
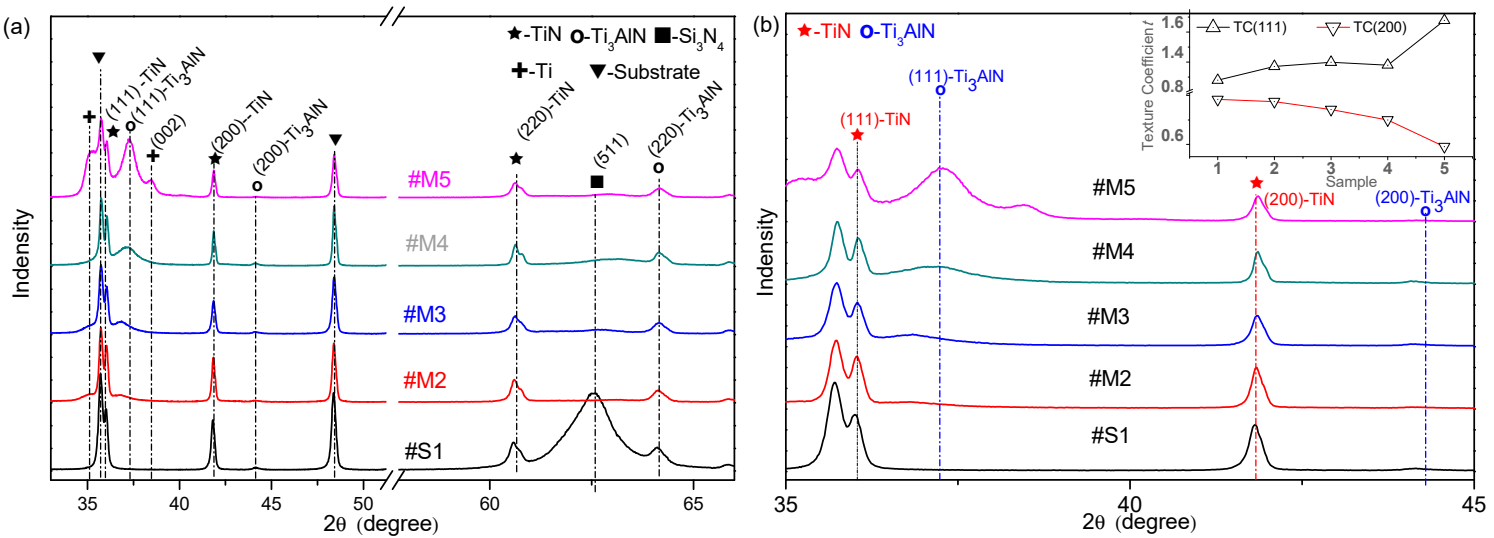

Figure 5. (a) The X-ray diffractometry patterns of monolayer TiAlSiN and TiAlSiN/Ti multilayer coatings (b) Enlargement of (111) and (200) peak.

In order to compare the planes of TiN phase more accurately, the texture coefficient $(T c)$ of $(111)$ and (200) planes is calculated by the method mentioned in reference [40]. As shown in Figure 5, the preferred orientation of all the coatings is (111) plane, and the (111) plane of TiN and TiAlN becomes stronger with the continuously increasing of the thickness of Ti layers. This can be explained by two reasons. One is the increase of thickness. Strain energy $U_{\mathrm{hkl}}$ increases linearly with the thickness of the coatings increasing [41]. However, (111) plane has the minimum strain energy, since at large thickness, it is more expected to appear (111) orientation to minimize the overall energy of the coatings. 
The other reason lies in the thermal strain. For the multilayer coatings, as the thickness of Ti layers increases, the thermal strain caused by the thermal expansion difference between TiAlSiN and Ti layers also increases gradually [42,43]. In this case, the strain energy of the coatings increases accordingly, which makes (111) peak become stronger.

From Figure 5b, it can be seen clearly that (200) peak becomes weaker with the thickness of the coatings increasing. This can be explained by the fact that at small film thickness, the coatings show obvious surface energy, while for thicker coatings, its strain energy replaces the surface energy and becomes dominant. Therefore, (200) peak with the minimum surface energy becomes weaker gradually. Moreover, compare monolayer coating with multilayer coatings, the former has higher compressive stress as shown in Table 1, which leads to a lattice parameters $(\alpha)$ shrink, enabling the number of broken bonds per square centimeter $\left(n_{\mathrm{hkl}}\right)$ to increase accordingly. Therefore, the monolayer coating (\#S1) has a higher surface energy (refer to Equation (2)) and stronger (200) plane than the multilayer coatings. Besides, as expected, the diffraction intensity of Ti becomes stronger as the thickness of Ti layers increases (Figure 5a), which indicates that the crystallinity of Ti is gradually increasing. This result is consistent with the finding of SEM result in Figure 4e.

In order to investigate the influence of TiAlSiN/Ti multilayer structure on residual stress, the residual stress of the film-substrate interface was evaluated by analyzing the substrate WC peak with $2 \theta-\sin ^{2} \psi$ method. Residual stress values of the sample substrates are shown in Table 1 All the residual stresses of substrates are in the compressive state. It can be seen that the compressive stress $(-78 \mathrm{MPa})$ of the substrate with the TiAlSiN monolayer coating (\#S1) is higher than that detected in substrates with multilayer coatings. a possible explanation for this phenomenon may be that the $\mathrm{Ti}$ layer can contribute to the stress relief of multilayer systems [9,44], but the thickness of \#M2 (25 nm) does not have enough volume to release the stress of TiAlSiN coatings. This result is compatible with the results provided by Vogli.et al. [45].

\subsection{Hardness Analysis}

The hardness and mechanical properties of TiAlSiN/Ti multilayer coatings with various $\mathrm{Ti}$ thicknesses, tested by CSM-mode, are shown in Figure 6 and Table 1. The average hardness is calculated with the platform in the depth range of 50 to $300 \mathrm{~nm}$. As expected, the monolayer TiAlSiN coating (\#S1) had the highest hardness (34 GPa), and it formed a platform in the depth range of 100-300 nm. For multilayer coatings, the hardness and modulus decreased with Ti thickness increasing from 25 to $150 \mathrm{~nm}$. This result could be explained by the effect of the softer layer Ti, as the rule of mixture (RM) (Equation (3)).

$$
H_{\mathrm{RM}}=\frac{t_{\mathrm{TiAlSiN}}}{\lambda} \cdot H_{\mathrm{TiAlSiN}}+\frac{t_{\mathrm{Ti}}}{\lambda} \cdot H_{\mathrm{Ti}}
$$

where $H_{\mathrm{RM}}$ is the hardness resulting from the rule of mixture, $t_{\mathrm{TiAlSiN}}$ and $t_{\mathrm{Ti}}$ is the thickness of TiAlSiN $\left(270 \mathrm{~nm}\right.$ ) and Ti sublayers, $H_{\mathrm{TiAlSiN}}$ and $H_{\mathrm{Ti}}$ is the hardness of TiAlSiN (34 GPa) and Ti (7.5 GPa) single layer, and $\lambda$ is the bilayer period. Compare the experimental values $(H)$ with predicted value $\left(H_{\mathrm{RM}}\right)$ of hardness (Table 1). In those coatings, monolayer TiAISiN coating \#S1 has the widest platform in the depth range of 50 to $300 \mathrm{~nm}$. An interesting phenomenon found is that the hardness of \#M5 shows a second platform (see Figure 6) in the depth range of 60 to $140 \mathrm{~nm}$. This indicates that fracture occurs on the surface of coatings when the indenter is pressed into \#M5 coating, which is well consistent with the result produced by fracture toughness test (see Figure $7(\mathrm{e}-\mathrm{x})$ ). The mechanism of cracking will be elaborated in FEM analysis. 


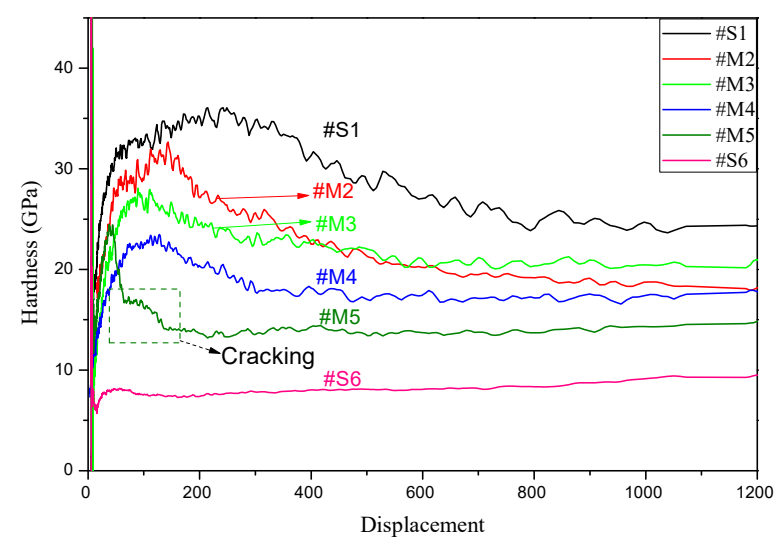

Figure 6. Hardness of coatings with the tip displacement at (0 1200 nm), \#S1 (Ti-0 nm), \#M2 (Ti-25 nm), \#M3 (Ti-50 nm), \#M4 (Ti-100 nm), \#M5 (Ti-150 nm), \#S6 (Ti monolayer coating).
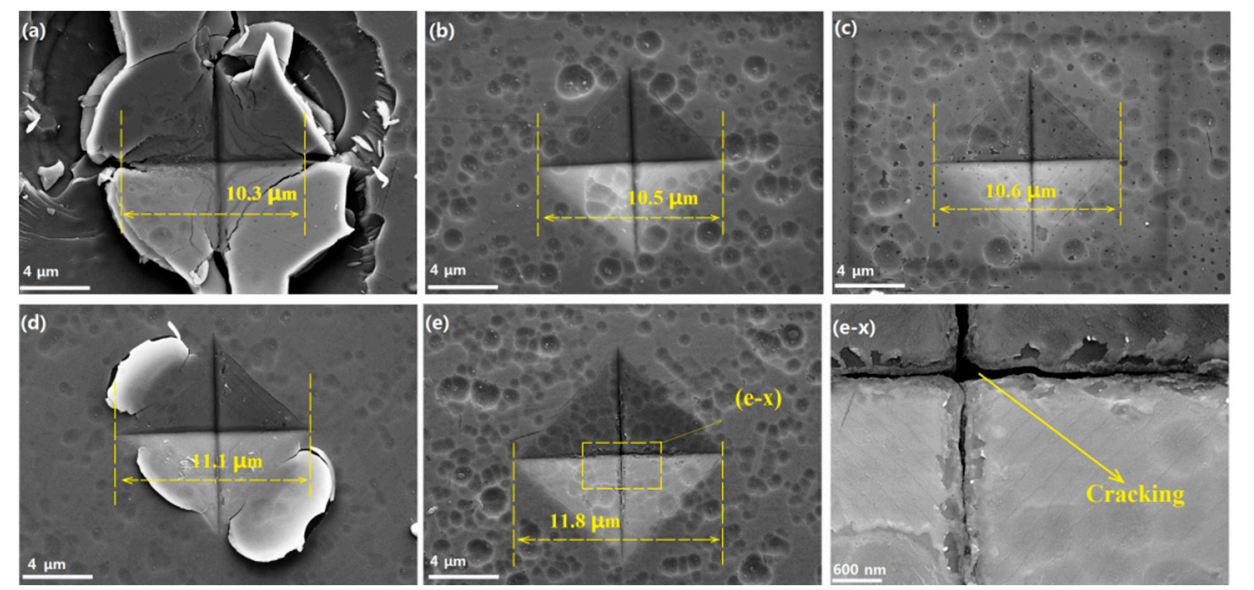

Figure 7. The surface morphology of the indentation generated by Vickers indenter with the load of 100 g. (a) \#S1 (Ti-0 nm), (b) \#M2 (Ti-25 nm), (c) \#M3 (Ti-50 nm), (d) \#M4 (Ti-100 nm), (e) \#M5 (Ti-150 nm), (e-x) partial enlarged image of (e).

\subsection{Toughness and Adhesion Analysis}

It is known that fracture characteristics of the film depend on material properties such as adhesion, hardness, residual stress, plasticity and thickness of the coatings $[45,46]$. In this work, since all the coatings were deposited on the same substrate, the difference of fracture characteristics could only be caused by different properties of the coatings. Figure 7 presents the surface morphology of the indentation generated by Vickers indenter with a load of $100 \mathrm{~g}$. It can be seen that the monolayer TiAlSiN coating (\#S1) exhibits obvious cracking, which is attributed to its high hardness and residual stress. Moreover, the diagonal of the indentation grows longer as the thickness of Ti layers in multilayer coatings increases, which results from that fact that the declined coating hardness enables the indenter to be pressed deeper. Compare the fracture toughness of multilayer coatings with that of monolayer coatings, we can see a significant improvement in the fracture toughness in the former. There are two reasons for that. Firstly, in TiAlSiN/Ti multilayer coatings, the cracks will be deflected when they pass through the interfaces. Secondly, the plastic deformation and ductile bridging of the Ti layer can dull and weaken the cracks, which will cause extra energy consumption and dissipation during crack propagation, thus contributing to the enhancement of fracture toughness [47,48].

However, as the thickness of the Ti layer increases, the fracture toughness will be reduced as shown in Figure 7, which is ascribed to plasticity mismatch. The reason is that when the indenter is pressed into TiAlSiN/Ti coatings, the Ti layer will undergo a severe plastic deformation whereas TiAlSiN sublayer has a small deformation due to its hard and brittle characteristics. In this case, the multilayer 
coatings will crack when the difference between TiAlSiN and Ti layers plastic deformation exceeds a certain value. Moreover, the \#M5, the coating with the thickest Ti layer, has deep cracks at the junction of diagonal inside the indentations where they have the maximum deformation curvature of the coatings.

The morphology of Rockwell indentations on coatings is presented in Figure 8. It can be seen that the monolayer TiAlSiN coating exhibits severe flaking (HF6) while for multilayer coatings, when the Ti thickness is $25 \mathrm{~nm}$, there are only a few cracks and tiny detachments, indicating excellent adhesion strength. However, the adhesion becomes worse as the thickness of the Ti layer increases. \#M4 shows the most obvious flaking among all the multilayer coatings. Samples \#M2 to \#M5 can be classified as HF2, HF4, HF6, and HF5 respectively listed in Table 1, which is consistent with the result in toughness analysis. According to Figure 8, the type of coating flaking of monolayer coating is different from that of multilayer coating, as evidenced by the fact that the flaking areas of monolayer coatings keep a certain distance from the edge of the indentation, as shown in Figure 8a, while that of the multilayer coatings are adjacent to the peripheral edge of the indentation. Since the indentation edge has the largest shape variable, the TiAlSiN sublayer and the Ti sublayer will be separated (as shown in Figure 8e-x) at this area due to the large difference in deformation, which is consistent with the fracture morphology of \#M5 (Figure 7e-x) observed in the toughness test.
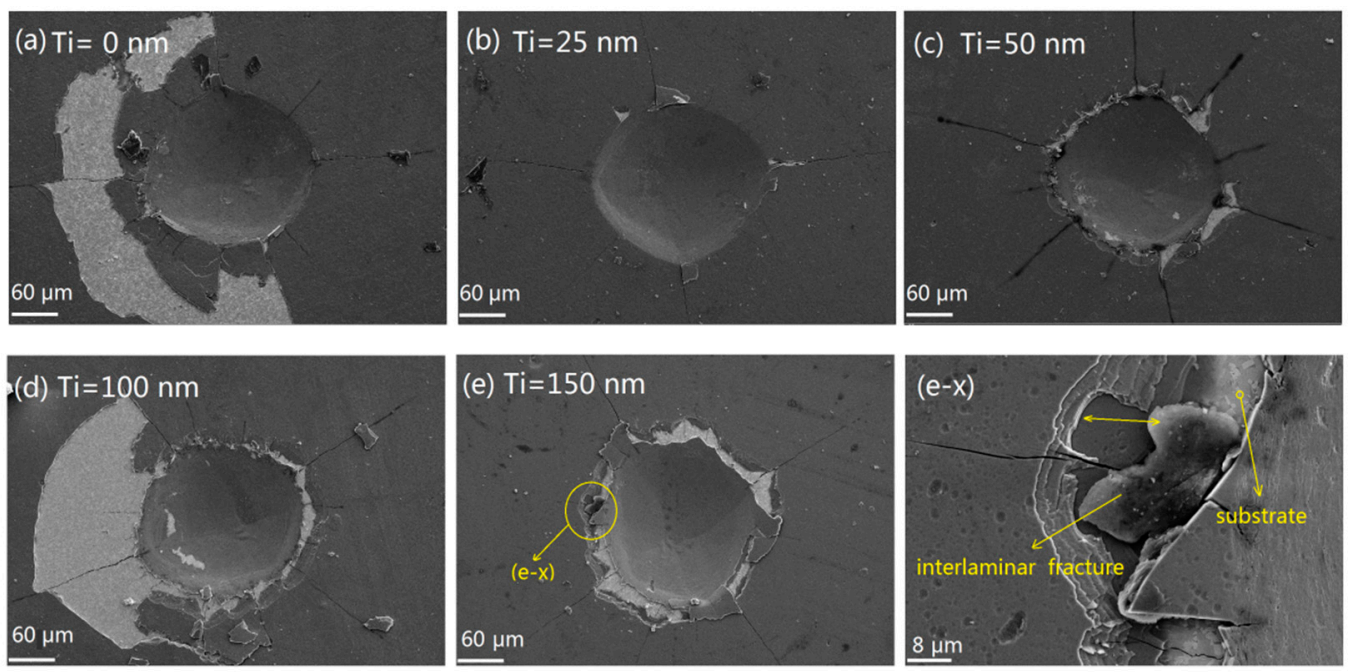

Figure 8. Rockwell indentation images of sample (a) \#S1 (Ti-0 nm), (b) \#M2 (Ti-25 nm), (c) \#M3 (Ti-50 nm), (d) \#M4 (Ti-100 nm), (e) \#M5 (Ti-150 nm), (e-x) partial enlarged image of (e).

\subsection{Computational Aspects}

When Berkovich indenter is pressed to $600 \mathrm{~nm}$, Von Mises stress distribution for coatings is shown in Figure 9, from which it can be seen clearly that the stress distribution for monolayer coatings shows gradient semi-circle behavior while the semi-circle edge becomes jagged for multilayer coatings. Moreover, this behavior becomes increasingly prominent as the thickness of the Ti layer increases, indicating that Ti layers with larger thickness can worsen the uniformity of stress distribution within the multilayer coatings. As displayed in Figure 9, the right bottom of each picture provides an enlarged image of zones where have the maximum Von Mises stress, in which the red semi-circle part represents high stress zones, which means the stress is greater than or equal to $1.8 \times 10^{5} \mathrm{~Pa}$. According to Figure 9 , the monolayer coatings have the largest high stress zone, while for multilayer coatings, the high stress zone reduces with the increase of $\mathrm{Ti}$ layer thickness, indicating that the coatings with thicker Ti layers are under less stress. This changing pattern can also explain the phenomenon that coatings hardness decreases with the thickness of Ti layers increasing. 


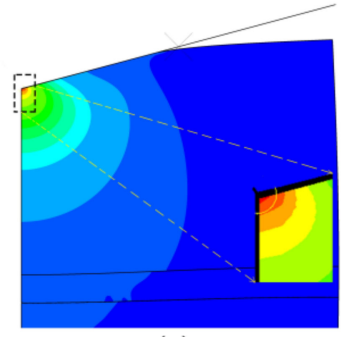

(a)

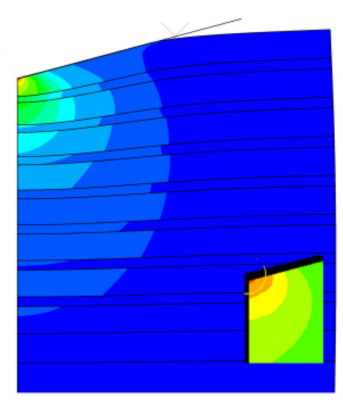

(d)

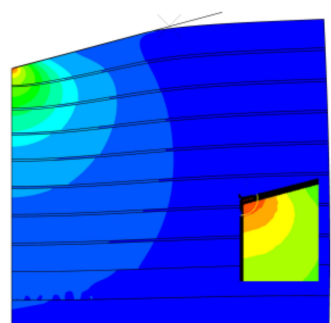

(b)

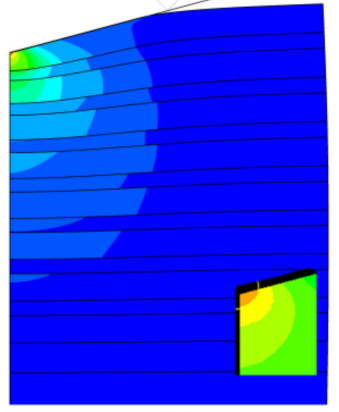

(e)

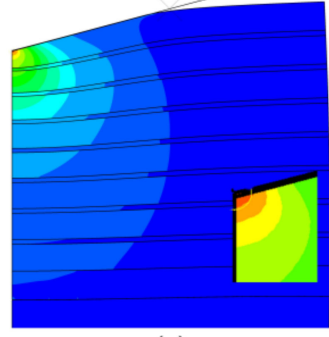

(c)

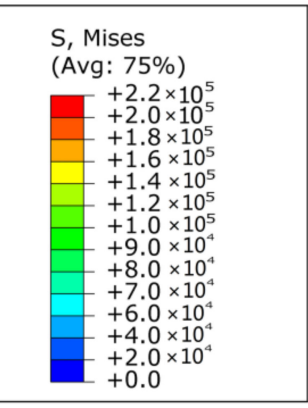

Figure 9. Contours of the Von Mises stress generated in TiAlSiN monolayer coatings and TiAlSiN/Ti multilayer coatings (a) \#S1 (Ti-0 nm), (b) \#M2 (Ti-25 nm), (c) \#M3 (Ti-50 nm), (d) \#M4 (Ti-100 nm), (e) \#M5 (Ti-150 nm), (e-x) the partial enlarged image of (e), the stress unit is in Pa.

To illustrate the effect of Ti layer thickness of the stress distribution within coatings more clearly, Von Mises stress distribution of coatings along the symmetric axis from the top surface to the substrate was plotted in Figure 10a. To identify the Von Mises stress distribution clearly, the stress distribution of the coatings ranging from 0 to $550 \mathrm{~nm}$ was enlarged in Figure 10b. According to Figure 10, when the indenter is pressed to the same depth $(600 \mathrm{~nm})$, the higher of Ti layer thickness is, the less stress will be applied to the coatings, which is consistent with the change of pressed depth (the diagonal length of the indentations) in the toughness analysis (Figure 7).

(a)

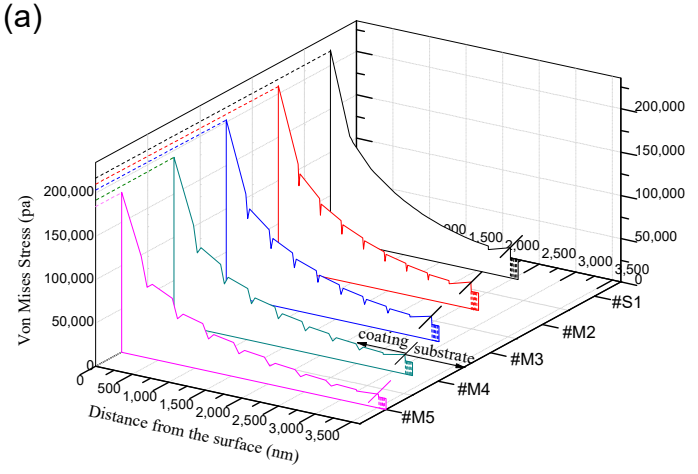

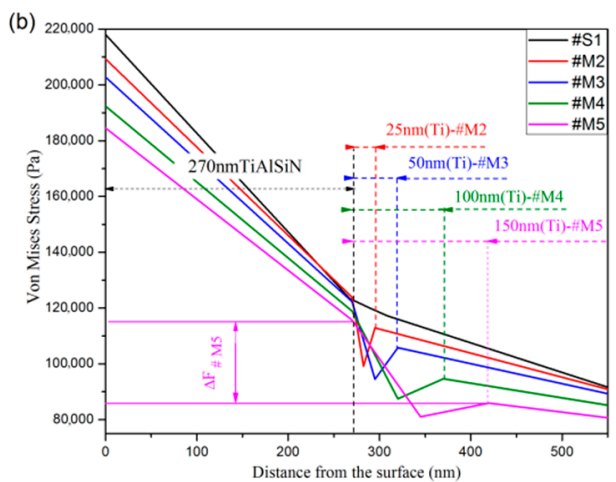

Figure 10. (a) Von Mises stress distribution along the symmetric axis from the top surface to the substrate, (b) the Von Mises stress in the depth range of 0 to $100 \mu \mathrm{m}$. $\Delta F$ is the Von Mises stress difference between the upper and lower interfaces of Ti layer.

At a small Ti layer thickness, the toughness of the coating is ameliorated due to interfaces, plastic deformation and ductile bridging [22,46]. However, the toughness is reduced with the increase of the thickness of Ti layers, which can be explained as follows. For TiAlSiN/Ti multilayer coatings, since the plasticity of Ti layers is greater than that of TiAlSiN layers (see Table 1), the coating with thicker Ti layers has larger plastic mismatch between Ti and TiAlSiN layers. When the indenter is pressed into the coatings to the same depth, as shown in Figure 10b, the multilayer coatings with thicker Ti layers 
have a larger $\Delta F,(\Delta F$ represents the Von Mises stress difference between the upper and lower interfaces of Ti layer), and when the stress components of $\Delta F$ along the interfaces are greater than the interlaminar bonding strength of TiAlSiN and Ti interlayers, cracks will occur between interlayers, resulting in worse toughness. Moreover, this rule can also expound the fracture behavior observed in \#M5 coating (Figure 6) in the hardness test.

Therefore, it can be concluded that the effect of $\mathrm{Ti}$ layer thickness on toughness results from the combination of multilayer toughening mechanism and plastic mismatch mechanism. When the thickness of Ti layers is small, the toughness of the coatings will be significantly improved owing to the dominance of multilayer toughening mechanism. However, as the thickness of the coatings increases gradually, the plastic mismatch between individual layers becomes increasingly obvious, resulting in decreased toughness and interlaminar fracture.

\subsection{Cutting Experimental}

The tool flank wear $V b$ versus the turning length was plotted in Figure 11a for five coatings with different Ti thicknesses. According to Figure 11a, it can be concluded that tool flank wear $V b$ of the coated tools can be decreased effectively by TiAlSiN/Ti multilayer structure, and that tool flank wear changes significantly with varying thicknesses of Ti layers. There are various characteristics of the coating, including microstructure, hardness, adhesion, toughness, etc., that can influence the cutting performance. To analyze the relationship between mechanical properties and wear morphology more accurately, the wear morphology of tool flank wear was observed by SEM, as shown in Figure 12a, from which it can be seen that the main damage forms of the coatings are abrasive wear and coating spalling. Then the tool flank wear edge is further divided into wear edge and spalling edge as illustrated in Figure 12b, where $W$ represents the sum of length of the wear edges $(w)$ protecting tools that are subjected to normal abrasive wear, $S$ represents the sum of length of spalling edges (s) from the tool, and coatings in this area are not involved in the cutting process, and $k$ represents $W$ versus $S$. Furthermore, the influence distance $(d)$ of the coating spalling caused by broken WC particles was analyzed in Figure $12 \mathrm{~b}$.
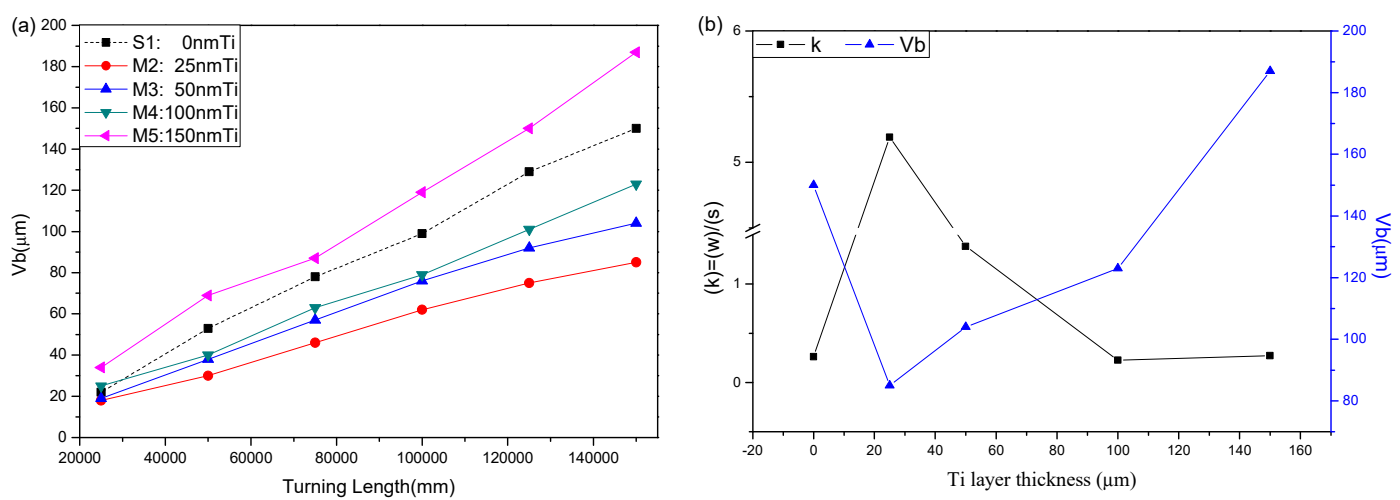

Figure 11. (a)Tool flank wear $V b$ curve versus cutting length of different coated tools. (b) Tool flank wear $V b$ and length ratio $k$ curve versus Ti layers thickness of different coated tools, $k=W / S=\sum(w) / \sum(s)$. 
(I)
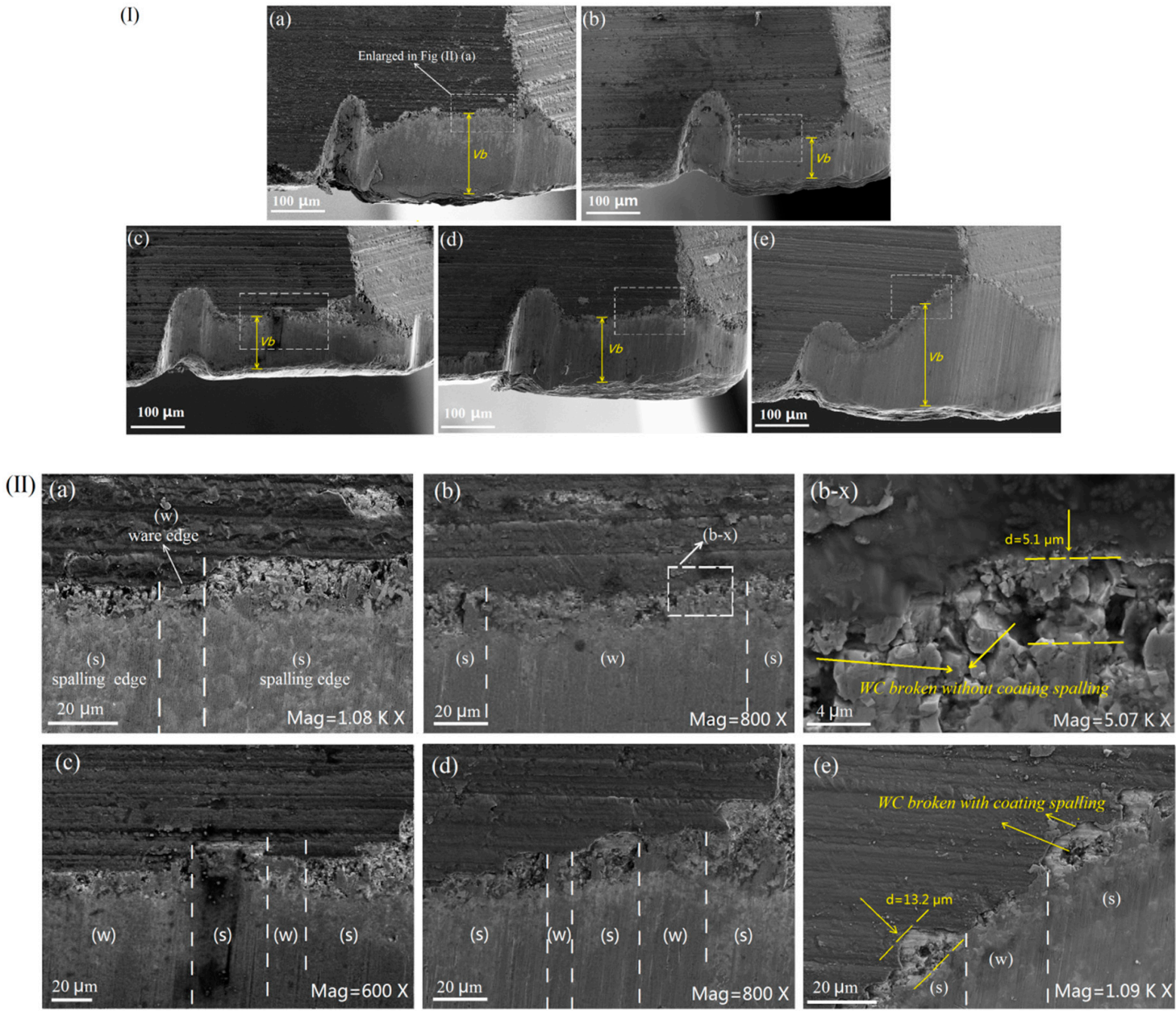

Figure 12. (I) Tool flank wear profiles of different coatings. (II) The partial enlarged image of (I) (a) \#S1 (Ti-0 nm), $V b_{\# S 1}=150 \mu \mathrm{m},(\mathbf{b}) \# \mathrm{M} 2(\mathrm{Ti}-25 \mathrm{~nm}), V b_{\# \mathrm{M} 2}=85 \mu \mathrm{m},(\mathbf{c}) \# \mathrm{M} 3$ (Ti-50 nm), $V b_{\# \mathrm{M} 3}=104 \mu \mathrm{m}$,

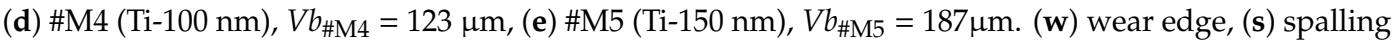
edge, $\mathrm{W}=\sum(w), \mathrm{S}=\sum(\mathrm{s})$, (d) influence distance of the coating spalling cause by broken WC.

As is shown in Figure 11a, \#M2 exhibit the minimum $V b$ and spalling edge due to excellent toughness and relatively higher hardness. a comparison between \#M3 and \#S1 in Figure 11a shows that, although the coating hardness of \#S1 is higher than that of \#M3, tool flank wear of \#S1 is greater than that of \#M3, indicating that in the cutting process of Inconel 718, the coating hardness is not a key factor influencing tool flank wear. According to Figure 11b, the coatings with high $k$ value like \#M2 and \#M3 demonstrate low tool flank wear, which is ascribed to the high toughness of the coatings. In the cutting process, there are lots of carbides (such as $\mathrm{TiC}, \mathrm{VC}, \mathrm{NbC}, \mathrm{WC}, \mathrm{TiN}, \mathrm{VN}, \mathrm{NbN}$ ) and dispersedly distributed interphase compounds (FeCr, CoCr, FeCrMo) within Inconel 718 [49,50]. Those compounds can easily combine with $\mathrm{C}$ or $\mathrm{N}$ element coming from the cutting fluid or air to generate dispersedly distributed hard phases at elevated temperatures. During the cutting operations, these hard phases will produce intensive shock load intermittently on the surface of the coatings. It can be seen from Figure 12 that broken WC particles occur on tools. This can be explained by the fact that since Co element serving as the blinder in the cemented carbide tools and Ni and Fe elements are VIIIB group elements, they have high chemical affinity at elevated temperatures so as to produce diffusive wear, which contributes to the loss of Co element, thus resulting in broken WC particles. The broken WC particles will cause the spalling of the coatings within certain influence distance $(d)$. As shown in Figure 12(II), \#M5 has wider influence distance (d) than \#M2, which is not even affected by the cracking and still belongs to the wear edge $(w)$ due to its high toughness. 
Abrasive wear is the main wear mechanism within wear zone. Since severe work hardening phenomenon occurs during the Inconel 718 cutting due to metallurgical (phase) changes [51] resulting from plastic deformation, the coatings with higher hardness are required to decrease the wear rate. For example, although there is no significant difference in the $\mathrm{k}$ value of \#S1 and \#M5, \#M5 demonstrates more serious flank wear as \#S1 coatings have higher hardness. Moreover, notch wear is observed at the tool flanks during the cutting of Inconel 718, which is ascribed to two reasons. Firstly, notch wear occurs in the fringe area where the tool flank is in contact with the unfinished metal surface, which has a high stress gradient. Secondly, the cutting burrs formed on the unfinished and finished metal surfaces can also lead to serious notch wear in this zone.

It can be found that in these coatings, the hardness of the coatings decreases, and plasticity increases with the thickness of inserted Ti layers increasing. In addition, although the multilayer structure can reduce residual stresses in the coatings, no regular relationship between residual stresses of the coatings and the thickness of Ti layers is observed. In addition, in indentation tests involved three kinds of indenters (Berkvich, Vickers and Rockwell indenter), the coating \#M5 with a Ti layer whose thickness is $150 \mathrm{~nm}$ exhibits cracking due to the plastic mismatch between Ti layers and TiAlSiN layers. In all coatings, \#M2 can help the coatings maintain high toughness without sacrificing too much hardness, and it also has the lowest flank wear in the cutting, which demonstrates that inserting Ti layers with suitable thickness is an effective way to improve the cutting performance of coated tools in cutting Inconel 718. Moreover, a comparison of flank wear of the coated tools reveals that the coating hardness of tools used in cutting Inconel 718 should be improved as much as possible under conditions that high toughness is maintained, thereby extending tool life.

\section{Conclusions}

In this paper, a series of TiAlSiN/Ti multilayer coatings with different Ti layer thicknesses $(0 \mathrm{~nm}$, $25 \mathrm{~nm}, 50 \mathrm{~nm}, 100 \mathrm{~nm}, 150 \mathrm{~nm}$ ) were prepared by high power impulse magnetron sputtering (HiPIMS), the effect of different coatings on mechanical properties was investigated and the mechanism was further expounded by means of the finite element method (FEM). Finally, the cutting performance of coated tools with TiAlSiN/Ti multilayer coatings was studied by the cutting experiment against Inconel 718. The main conclusion can be reached as follows.

(1) The varying thicknesses of the Ti layer can bring obvious changes to the properties of the coatings. When the thickness increases, the hardness and elastic modulus decrease significantly from $34 \mathrm{GPa}, 367 \mathrm{GPa}$ to $21 \mathrm{GPa}, 227 \mathrm{GPa}$, respectively, and the plasticity increases from 0.43 to 0.68 . In addition, the multilayer coatings with Ti layers can reduce the residual compressive stress of TiAlSiN coatings, which can be explained by the fact that in TiAlSiN/Ti multilayer coatings, the stress of the hard layer TiAlSiN/Ti can be released to the Ti layer.

(2) The high brittleness of TiAlSiN can be markedly improved by introducing Ti layers, and the improvement degree changes with varying thickness of Ti layers. When the thickness of Ti layers is small, the interfaces within the coatings and plastic deformation, and ductile bridging of Ti layers can result in significant improvement of the toughness of the coatings. However, if the thickness of Ti layer continues to increase, the greater interlayer stress difference and plasticity mismatch will result in cracking of the coatings in areas where have the largest deformation, resulting in the declined toughness of the coatings. After experiments, it was found that the coatings with Ti layers whose thickness is $25 \mathrm{~nm}$ (\#M2) exhibit the excellent toughness without sacrificing too much hardness.

(3) The cutting experiment the performance of TiAlSiN can be significantly enhanced by inserting Ti interlayer, and the coatings with high toughness also exhibit good cutting performance, which is ascribed to the fact that the coatings will suffer from intensive shock load of hard phases precipitated by Inconel 718 at elevated temperature.

Author Contributions: G.L., L.L. and S.L. conceived and designed the experiments; G.L., L.W., J.G. and J.J. analyzed the data; G.L., M.H. and H.M. performed the FEM; and G.L. wrote the paper. 
Funding: This research was funded by National Science and Technology Major Project, No.04: $2014 Z$ X04012012.

Acknowledgments: The authors would like to thank Xiaocong Kuang, Meng Ai and Kai Huang for their assistance of performing the experiments.

Conflicts of Interest: The authors declare no conflict of interest.

\section{References}

1. Bhatt, A.; Attia, H.; Vargas, R.; Thomson, V. Wear mechanisms of WC coated and uncoated tools in finish turning of Inconel 718. Tribol. int. 2010, 43, 1113-1121. [CrossRef]

2. Liu, Z.F.; Peng, L.; Lv, Z.D. Study on Tool Wear of Indexable Coating Inserts for Turning Inconel 718. Adv. Mater. Res. 2012, 583, 259-262. [CrossRef]

3. He, L.J.; Xu, J.H.; Su, H.H.; Chen, Y. Turning of cast in conel 718 with coated carbide and whisker reinforced ceramic tools. Mater. Sci. Forum 2013, 770, 136-140. [CrossRef]

4. Barthelma, F.; Frank, H.; Schiffler, M.; Bartsch, A. Hard coatings to improve the machining of nickel based materials. Procedia CIRP 2016, 46, 294-298. [CrossRef]

5. Ucun, I.; Aslantas, K.; Gokce, B.; Bedir, F. Effect of tool coating materials on surface roughness in micromachining of Inconel 718 super alloy. Proc. Inst. Mech. Eng. Part B J. Eng. Manuf. 2014, 228, 1550-1562. [CrossRef]

6. Akhtar, W.; Sun, J.; Chen, W. Effect of Machining Parameters on Surface Integrity in High Speed Milling of Super Alloy GH4169/Inconel 718. Mater. Manuf. Process 2016, 31, 620-627. [CrossRef]

7. Akhyar Ibrahim, G.; Che Haron, C.H.; Abdul Ghani, J.; Said, A.Y.M.; Abu Yazid, M.Z. Performance of PVD-Coated carbide tools when turning in conel 718 in dry machining. Adv. Mech. Eng. 2015, 3, 790975. [CrossRef]

8. Sui, X.; Li, G.; Qin, X.; Yu, H.; Zhou, X.; Wang, K.; Wang, Q. Relationship of microstructure, mechanical properties and titanium cutting performance of TiAlN/TiAlSiN composite coated tool. Ceram. Int. 2016, 42, 7524-7532. [CrossRef]

9. Jiang, C.L.; Zhu, H.L.; Shin, K.S.; Tang, Y.B. Influence of titanium interlayer thickness distribution on mechanical properties of Ti/TiN multilayer coatings. Thin Solid Films 2017, 632, 97-105. [CrossRef]

10. Sun, D.; Liu, H.; Zeng, X.; Zhang, S.; Huang, J. Effect of Al content on microstructure and mechanical properties of Ti-Al-Si-N nanocomposite coatings. Int. J. Refract. Met. Hard Mater. 2019, 19, 199-205.

11. Anwar, S.; Islam, A.; Anwar, S. Mechanical studies of thermally annealed nc-W2N embedded a-Si3N4 nanocomposite films. Thin Solid Films 2017, 636, 93-98. [CrossRef]

12. Feng, C.; Hu, S.; Jiang, Y.; Wu, N.; Li, M.; Xin, L.; Zhu, S.; Wang, F. Effects of Si content on microstructure and mechanical properties of TiAlN/Si3N4-Cu nanocomposite coatings. Appl. Surf. Sci. 2014, 320, 689-698. [CrossRef]

13. Zhu, L.; Hu, M.; Ni, W.; Liu, Y. High temperature oxidation behavior of Ti0.5Al0.5N coating and Ti0.5Al0.4Si0.1N coating. Vacuum 2012, 86, 1795-1799. [CrossRef]

14. Chen, T.; Xie, Z.; Gong, F.; Luo, Z.; Yang, Z. Correlation between microstructure evolution and high temperature properties of TiAlSiN hard coatings with different Si and Al content. Appl. Surf. Sci. 2014, 314, 735-745. [CrossRef]

15. Su, K.; Liu, D.; Pang, H.; Shao, T. Improvement on thermal stability of TiAlSiN coatings deposited by IBAD. Surf. Eng. 2018, 34, 504-510. [CrossRef]

16. Tillmann, W.; Dildrop, M. Influence of Si content on mechanical and tribological properties of TiAlSiN PVD coatings at elevated temperatures. Surf. Coat. Technol. 2017, 321, 448-454. [CrossRef]

17. Tang, C.J.; Kong, D.J. Effects of wear speeds on friction-wear behaviours of cathode arc ion plated TiAlSiN coatings at high temperatures. Tribol. Mater. Surf. Interfaces 2017, 11, 66-74.

18. He, N.; Li, H.; Ji, L.; Liu, X.; Zhou, H.; Chen, J. High temperature tribological properties of TiAlSiN coatings produced by hybrid PVD technology. Tribol. Int. 2016, 98, 133-143. [CrossRef]

19. Kasim, M.S.; Che Haron, C.H.; Ghani, J.A.; Sulaiman, M.A.; Yazid, M.Z.A. Wear mechanism and notch wear location prediction model in ball nose end milling of Inconel 718. Wear 2013, 302, 1171-1179. [CrossRef]

20. Sui, S.; Chen, J.; Fan, E.; Yang, H.; Lin, X.; Huang, W. The influence of Laves phases on the high-cycle fatigue behavior of laser additive manufactured Inconel 718. Mater. Sci. Eng. A 2017, 695, 6-13. [CrossRef] 
21. Chen, H.; Zheng, B.C.; Li, Y.G.; Wu, Z.L.; Lei, M.K. Flexible hard TiAlSiN nanocomposite coatings deposited by modulated pulsed power magnetron sputtering with controllable peak power. Thin Solid Films 2019, 669, 377-386. [CrossRef]

22. Wang, Y.X.; Zhang, S. Toward hard yet tough ceramic coatings. Surf. Coat. Technol. 2014, 258, 1-16. [CrossRef]

23. Mori, T.; Noborisaka, M.; Watanabe, T.; Suzuki, T. Oxidation resistance and hardness of TiAlSiN/CrAlYN multilayer films deposited by the arc ion plating method. Surf. Coat. Technol. 2012, 213, 216-220. [CrossRef]

24. Treml, R.; Kozic, D.; Zechner, J.; Maeder, X.; Sartory, B.; Gänser, H.P.; Schöngrundner, R.; Michler, J.; Brunner, R.; Kiener, D. High resolution determination of local residual stress gradients in single- and multilayer thin film systems. Acta. Mater. 2016, 103, 616-623. [CrossRef]

25. Ali, R.; Sebastiani, M.; Bemporad, E. Influence of Ti-TiN multilayer PVD-coatings design on residual stresses and adhesion. Mater. Design 2015, 75, 47-56. [CrossRef]

26. Vogli, E.; Tillmann, W.; Selvadurai-Lassl, U.; Fischer, G.; Herper, J. Influence of Ti/TiAlN-multilayer designs on their residual stresses and mechanical properties. Appl. Surf. Sci. 2011, 257, 8550-8557. [CrossRef]

27. Bonu, V.; Jeevitha, M.; Kumar, V.P.; Barshilia, H.C. Nanolayered multilayer Ti/TiN coatings: Role of bi-layer thickness and annealing on solid particle erosion behaviour at elevated temperature. Surf. Coat. Technol. 2019, 357, 204-211. [CrossRef]

28. Kouznetsov, V.; Macák, K.; Schneider, J.M.; Helmersson, U.; Petrov, I. a novel pulsed magnetron sputter technique utilizing very high target power densities. Surf. Coat. Technol. 1999, 122, 290-293. [CrossRef]

29. Anders, A. a review comparing cathodic arcs and high power impulse magnetron sputtering (HiPIMS). Surf. Coat. Technol. 2014, 257, 308-325. [CrossRef]

30. De Monteynard, A.; Schuster, F.; Billard, A.; Sanchette, F. Properties of chromium thin films deposited in a hollow cathode magnetron powered by pulsed DC or HiPIMS. Surf. Coat. Technol. 2017, 330, 241-248. [CrossRef]

31. Wang, Z.; Zhang, D.; Ke, P.; Liu, X.; Wang, A. Influence of substrate negative bias on structure and properties of TiN coatings prepared by hybrid HIPIMS method. J. Mater. Sci. Technol. 2015, 31, 37-42. [CrossRef]

32. Ma, Q.; Li, L.; Xu, Y.; Ma, X.; Xu, Y.; Liu, H. Effect of Ti content on the microstructure and mechanical properties of TiAlSiN nanocomposite coatings. Int. J. Refract. Met. Hard Mater. 2016, 59, 114-120. [CrossRef]

33. Hoshyarmanesh, H.; Nehzat, N.; Salehi, M.; Ghodsi, M. X-ray diffraction measurement of residual stress in sol-gel grown lead zirconate titanate thick films on nickel-based super alloy substrate. J. Mech. Sci. Technol. 2015, 29, 715-721. [CrossRef]

34. Huen, W.Y.; Lee, H.; Vimonsatit, V.; Mendis, P.; Lee, H. Nanomechanical properties of thermal arc sprayed coating using continuous stiffness measurement and artificial neural network. Surf. Coat. Technol. 2019, 366, 266-276. [CrossRef]

35. Chen, X.; Du, Y.; Chung, Y. Commentary on using H/E and H3/E2 as proxies for fracture toughness of hard coatings. Thin Solid Films 2019. [CrossRef]

36. Wang, S.Q.; Chen, L.; Yang, B.; Chang, K.K.; Du, Y.; Li, J.; Gang, T. Effect of Si addition on microstructure and mechanical properties of Ti-Al-N coating. Int. J. Refract. Met. Hard Mater. 2010, 28, 593-596. [CrossRef]

37. Jose, F.; Ramaseshan, R.; Dash, S.; Sundari, T.S.; Jain, D.; Ganesan, V.; Chandramohan, P.; Srinivasan, M.P.; Tyagi, A.K.; Raja, B. Significance of Al on the morphological and optical properties of Ti1- $x \mathrm{Al} x \mathrm{~N}$ thin films. Mater. Chem. Phys. 2011, 130, 1033-1037. [CrossRef]

38. Devia, D.M.; Restrepo-Parra, E.; Arango, P.J.; Tschiptschin, A.P.; Velez, J.M. TiAlN coatings deposited by triode magnetron sputtering varying the bias voltage. Appl. Surf. Sci. 2011, 257, 6181-6185. [CrossRef]

39. Banerjee, T.; Chattopadhyay, A.K. Influence of substrate bias on structural and tribo-mechanical properties of pulsed magnetron sputtered TiN-WS $x$ hard-lubricious coating. Tribol. Int. 2018, 123, 81-91. [CrossRef]

40. Staia, M.H.; Puchi, E.S.; Lewis, D.B.; Cawley, J.; Morel, D. Microstructural characterization of chemically vapor deposited TiN coating. Surf. Coat. Tech. 1996, 86, 432-437. [CrossRef]

41. Pelleg, J.; Zevin, L.Z.; Lungo, S.; Croitoru, N. Reactive-sputter-deposited TiN films on glass substrates. Thin Solid Films 1991, 197, 117-128. [CrossRef]

42. Rogström, L.; Ullbrand, J.; Almer, J.; Hultman, L.; Jansson, B.; Odén, M. Strain evolution during spinodal decomposition of TiAlN thin films. Thin Solid Films 2012, 520, 5542-5549. [CrossRef]

43. Ehrlich, A.; Weiß, U.; Hoyer, W.; Geßner, T. Microstructural changes of Pt/Ti bilayer during annealing in different atmospheres-an XRD study. Thin Solid Films 1997, 300, 122-130. [CrossRef] 
44. Lei, S.; Huang, J.; Chen, H. Measurement of residual stress on TiN/Ti bilayer thin films using average X-ray strain combined with laser curvature and nanoindentation methods. Mater. Chem. Phys. 2017, 199, 185-192. [CrossRef]

45. Sebastiani, M.; Johanns, K.E.; Herbert, E.G.; Pharr, G.M. Measurement of fracture toughness by nanoindentation methods: Recent advances and future challenges. Curr. Opin. Solid State Mater. Sci. 2015, 19, 324-333. [CrossRef]

46. Mofidi, H.H.; Sabour Rouhaghdam, A.; Ahangarani, S.; Bozorg, M.; Azadi, M. Fracture toughness of TiN coating as a function of interlayer thickness. Adv. Mater. Res. 2014, 829, 466-470. [CrossRef]

47. Dang, C.; Li, J.; Wang, Y.; Chen, J. Structure, mechanical and tribological properties of self-toughening TiSiN/Ag multilayer coatings on Ti6Al4V prepared by arc ion plating. Appl. Surf. Sci. 2016, 386, 224-233. [CrossRef]

48. Yang, W.; Ayoub, G.; Salehinia, I.; Mansoor, B.; Zbib, H. Deformation mechanisms in Ti/TiN multilayer under compressive loading. Acta. Mater. 2017, 122, 99-108. [CrossRef]

49. Kuzin, V.V.; Volosova, M.A.; Fedorov, M.Y. Wear of tools from nitride ceramics when machining nickel-based alloys. J. Frict. Wear. 2013, 34, 199-203. [CrossRef]

50. Shokrani, A.; Dhokia, V.; Newman, S.T. Environmentally conscious machining of difficult-to-machine materials with regard to cutting fluids. Int. J. Mach. Tools Manuf. 2012, 57, 83-101. [CrossRef]

51. Zhou, J.; Bushlya, V.; Avdovic, P.; Ståhl, J.E. Study of surface quality in high speed turning of Inconel 718 with uncoated and coated CBN tools. Int. J. Adv. Manuf. Technol. 2012, 58, 141-151. [CrossRef]

(C) 2019 by the authors. Licensee MDPI, Basel, Switzerland. This article is an open access article distributed under the terms and conditions of the Creative Commons Attribution (CC BY) license (http://creativecommons.org/licenses/by/4.0/). 